\title{
Separating climate change signals into thermodynamic, lapse-rate and circulation effects: theory and application to the European summer climate
}

\author{
Nico Kröner ${ }^{1} \cdot$ Sven Kotlarski $^{1} \cdot$ Erich Fischer $^{1} \cdot$ Daniel Lüthi $^{1} \cdot$ Elias Zubler $^{2}$. \\ Christoph Schär ${ }^{1}$
}

Received: 18 December 2015 / Accepted: 14 July 2016 / Published online: 26 July 2016

(C) The Author(s) 2016. This article is published with open access at Springerlink.com

\begin{abstract}
Climate models robustly project a strong overall summer warming across Europe showing a characteristic north-south gradient with enhanced warming and drying in southern Europe. However, the processes that are responsible for this pattern are not fully understood. We here employ an extended surrogate or pseudo-warming approach to disentangle the contribution of different mechanisms to this response pattern. The basic idea of the surrogate technique is to use a regional climate model and apply a large-scale warming to the lateral boundary conditions of a present-day reference simulation, while maintaining the relative humidity (and thus implicitly increasing the specific moisture content). In comparison to previous studies, our approach includes two important extensions: first, different vertical warming profiles are applied in order to separate the effects of a mean warming from lapse-rate effects. Second, a twin-design is used, in which the climate change signals are not only added to present-day conditions, but also subtracted from a scenario experiment. We demonstrate that these extensions provide an elegant way to separate the full climate change signal into contributions from large-scale thermodynamic (TD), lapse-rate (LR), and circulation and other remaining effects $(\mathrm{CO})$. The latter in particular include changes in land-ocean contrast and spatial variations of the SST warming patterns. We find that the TD effect yields a large-scale warming across Europe with no distinct latitudinal gradient. The LR effect, which is quantified for the
\end{abstract}

Nico Kröner

nico.kroener@env.ethz.ch

1 Institute for Atmospheric and Climate Science, ETH Zurich, Universitätstrasse 16, 8092 Zurich, Switzerland

2 Center for Climate Systems Modeling (C2SM), ETH Zurich, Zurich, Switzerland first time in our study, leads to a stronger warming and some drying in southern Europe. It explains about $50 \%$ of the warming amplification over the Iberian Peninsula, thus demonstrating the important role of lapse-rate changes. The effect is linked to an extending Hadley circulation. The CO effect as inherited from the driving GCM is shown to further amplify the north-south temperature change gradient. In terms of mean summer precipitation the TD effect leads to a significant overall increase in precipitation all across Europe, which is compensated and regionally reversed by the LR and CO effects in particular in southern Europe.

Keywords Surrogate climate change $\cdot$ Regional climate modelling · Thermodynamic effects $\cdot$ Lapse-rate effects . Circulation effects

\section{Introduction}

The record-breaking summer heatwaves in 2003, 2006 and 2010 have raised interest of the scientific community in the European summer climate (Schär et al. 2004; Rebetez et al. 2009; Barriopedro et al. 2011). Observational studies show that European summer temperatures were rising in the last decades, especially in the upper percentiles (Della-Marta et al. 2007; Parey et al. 2010). Model simulations project that this trend will continue if greenhousegas concentrations continue to rise (Kjellstrom et al. 2007; Fischer and Schär 2009, 2010; Orlowsky and Seneviratne 2012; Kharin et al. 2013; Collins et al. 2013). Along with mean temperature changes, a strong drying for the Mediterranean region (Rowell and Jones 2006, ROW06 henceforth; Sanchez-Gomez et al. 2009; Kendon et al. 2010, KEN10 henceforth), changes of precipitation intensity and frequency (Rajczak et al. 2013; Ban et al. 2015) and increased 
temperature variability (Schär et al. 2004; Fischer et al. 2012; Cattiaux et al. 2015) are projected for many European regions. These changes are expected to have strong socio-economic and ecological impacts across Europe (Field et al. 2012; IPCC 2014).

Among the most peculiar characteristics of the European climate change signal is the pronounced north-south warming gradient, which includes a substantially stronger summer warming and drying in the Mediterranean and southern Europe in comparison to Central and Northern Europe. This pattern is robust across the overwhelming majority of global climate simulations (IPCC 2013). Indeed, unlike most other mid-latitude regions and other seasons which are projected to see a stronger warming at high latitudes (referred to as polar amplification) and an associated reduction of the tropospheric north-south temperature contrast, the projected summer warming over Europe has the opposite gradient and exhibits a more pronounced warming in the south. This could also have strong implications for temperature variability and extreme events (Schneider et al. 2015). The reasons for this anomalous latitudinal warming pattern have been investigated in a number of studies, but are still not fully understood. Some studies have invoked large-scale changes in circulation including an expansion of the Hadley cell and shift in storm tracks (Mbengue and Schneider 2013; Collins et al. 2013), some have addressed the thermodynamic effects of a generally warmer and moisture atmosphere (Rind et al. 1990; Manabe et al. 1992), some have pinpointed an enhanced land-sea contrast due to the delayed oceanic warming (Manabe et al. 1992; Gregory et al. 1997; Rowell and Jones 2006; Boe and Terray 2014), and others have argued with regional land-atmosphere feedback processes such as a stronger spring soil-moisture drying over southern Europe and/or regional soil-moisture atmosphere temperature and precipitation feedback processes (Schär et al. 1999; Seneviratne et al. 2006; Vidale et al. 2007; Boe and Terray 2014).

In terms of their origins, climate change effects are often classified into thermodynamically and dynamically-driven features. Thermodynamic changes include the large-scale warming of the atmosphere (Stocker et al. 2013) as well as an increase of specific humidity following the Clausius-Clapeyron relationship (Raval and Ramanthan 1989; DelGenio et al. 1991; Allen and Ingram 2002; Soden et al. 2005). These thermodynamic changes vary depending on latitude, longitude and height (Woollings 2008; Collins et al. 2013). The dynamic changes manifest themselves in changes of the atmospheric circulation and are more uncertain than the thermodynamic ones (Hall 2014; Shepherd 2014). The most robust projected changes include a shift of the storm tracks and a general shift of the mass distribution in the atmosphere (Barnes and Polvani 2013; Collins et al. 2013). Changes in temperature lapse-rates represent yet another factor, and these are usually categorized with either the thermodynamic or the dynamic effects. Models project that the warming in the tropics (and to a lesser extent in the mid-latitudes) proceeds faster in the upper than in the lower troposphere (Tett et al. 1996; Held and Soden 2000; Bony et al. 2006). This behaviour is due to convection (as the moist adiabatic lapse-rate decreases with temperature), and it implies a stabilization of the dry atmospheric stratification. While lapse-rate changes are broadly discussed in relation to the tropics, they have received only little attention in the assessment of European climate change. Here we will address this gap and try to quantify the role of lapse-rate changes for European climate change.

Several studies have tried to objectively discriminate between thermodynamic effects, dynamic effects and local feedbacks (e.g. ROW06; KEN10). Such efforts are complicated by the fact that all contributing factors are strongly interdependent. For instance, changes in the large-scale circulation may also cause changes in cloud cover and will therefore have strong influence on the surface radiative balance (van Ulden et al. 2007). Likewise, a recent analysis of the EURO-CORDEX (Jacob et al. 2014) experiments for example suggests that the occurrence of European summer heat waves results from complex interactions between soil moisture and large-scale circulation (Vautard et al. 2013).

In this study we exploit an extended version of the surrogate climate change or pseudo-warming methodology (SCC hereafter) to disentangle the different factors. An early version of this approach was introduced by Schär et al. (1996). The SCC gives the possibility to modify a given synoptic-scale atmospheric evolution by applying vertical warming and moistening profiles. The method was used to study heavy precipitation over Europe at a time where no comprehensive ensembles of climate projections were available (Frei et al. 1998). SCC scenarios were further used to investigate the processes behind summer drying in the mid-latitudes (Seneviratne et al. 2002, ROW06; KEN10). Im et al. (2010) used the method to quantify the role of thermodynamic feedbacks over the Alpine region. A surrogate approach was also employed by Rasmussen et al. (2011) to study the accelerated hydrological cycle over Colorado and by Sorland and Sorteberg (2015) to study monsoon low-pressure systems under climate change. This study will apply the SCC approach to systematically quantify the influence of individual large-scale drivers on projected changes of the European summer climate. For this purpose, state-of-the-art climate models are employed and the SCC is extended to a larger domain compared to previous works and to climatological time scales.

Im et al. (2010) and Frei et al. (1998), for instance, used much smaller modelling domains covering only parts of the European continent. This study thereby complements the extensive works of ROW06 and KEN10 who also looked at the entire European continent over climatological time 
scales using one individual atmospheric model at a comparatively low resolution. The generalisation of the results of such surrogate experiments is often limited because only one specific climate model was used. Therefore it is of great interest to perform similar studies with different climate models and this study contributes to this aim.

An very important methodological extensions with respect to previous work is, that we quantify the influence of large-scale lapse-rate changes by using the SCC methodology with different vertical profiles. Also we extend the idea of ROW06 in which the climate change signal is not only added to present-day conditions, but the different contributions are also systematically subtracted from the scenario experiment representing future conditions. This twindesign provides a very elegant way to separate the different effects.

The paper is structured as follows: in the second section a thorough explanation of the surrogate approach is given together with a description of the model setup. Section 3 presents the results of the surrogate experiments including a validation of the approach. Section 4 discusses the results, before ending with conclusions and an outlook.

\section{Methods}

\subsection{Introduction to surrogate climate change methodology}

The basic idea of the surrogate approach is to apply a largescale temperature change to the lateral boundary conditions of a present-day reference simulation of a regional climate model (RCM), while maintaining the relative humidity and thus increasing the specific moisture content. The relative humidity is held constant because observations and model studies suggest it would behave like this in a warmer climate (Cess et al. 1990; Ross et al. 2002; Allen and Ingram 2002; Soden et al. 2005). The mean temperature perturbation is taken from a mean climate change signal of the driving GCM run. The resulting surrogate climate follows the large-scale circulation of the reference period but with a warmer and more humid climate. In principle the approach allows to study the regional and local climate response and feedbacks in response to a thermodynamic change of the atmosphere, whereas the more uncertain dynamic response to climate change is excluded.

Because of dynamical constraints, the specified temperature change cannot be chosen arbitrarily. Schär et al. (1996) showed that by using $\Delta T=\Delta T(p)$, i.e. the temperature change is a function of pressure only, the equations of motions are not altered by this manipulation, and the flow remains unchanged except for implied changes and feedbacks, such as latent heating or changes in cloud cover. It is important to note that changes in horizontal temperature gradients are not included, because following the adjustment of the thermal wind relation the large-scale circulation would be altered. Structures that entail changes in the horizontal temperature gradients are thus considered to be part of the dynamic rather than thermodynamic changes.

Concerning the vertical dependency of $\Delta T(p)$, previous studies have shown that warming signals vary with height and are stronger at the tropopause than on the ground (Soden et al. 2005; Santer et al. 2008; Collins et al. 2013; Vallis et al. 2015). This is true for the tropics up to latitudes of $60^{\circ}$ north. Nevertheless, some of the early surrogate studies mentioned before used a vertically constant temperature perturbation (Schär et al. 1996; Seneviratne et al. 2002; Im et al. 2010), ignoring the lapse-rate change, whereas other studies accounted for it (ROW06; KEN10). However, none of these studies actually tested whether this lapse-rate change has an important influence on the European climate change. In this study we will exploit a general form of the surrogate framework. First, consideration will be given to a height-dependent temperature perturbation, in order to assess the importance of lapse-rate effects for the projected climate change signal. Second, in addition to warming experiments we will also employ experiments that add some cooling and drying to scenario experiments. As will be seen, the combination of warming and cooling experiments yields some validation of the methodology.

\subsection{Surrogate setup}

Our ensemble of surrogate experiments consists of six members. Two of them are reference runs CTRL and SCEN, in which the regional climate model CCLM (see Sect. 2.4) is nested into the GCM MPI-ESM-LR in conventional downscaling mode. The four other members are surrogate experiments. In order to make our surrogate experiments comparable to the reference runs, we calculate $\Delta T(p)$ as the area mean climate change signal extracted from the reference simulations:

$\triangle T=T_{S C E N}-T_{C T R L}$

In a first step we omit the height dependence of the warming (i.e. we do not consider large-scale lapse-rate changes) and choose the warming at $850 \mathrm{hPa}$ as representative for the whole atmosphere. In a second step we consider $\Delta T$ to be a function of height (as defined by the vertical model levels), explicitly accounting for changes in the large-scale lapse-rate. As the model considered doesn't use pressure coordinates, we used $\Delta T(z)$ instead of $\Delta T(p)$, but the associated violation of mass balance is negligible. Figure 1b shows $\Delta T(z)$ for both approaches. The variability of $\Delta T$ with the seasonal cycle is accounted for by calculating a smoothed mean annual cycle of $\Delta T$ (Fig. 1a). 


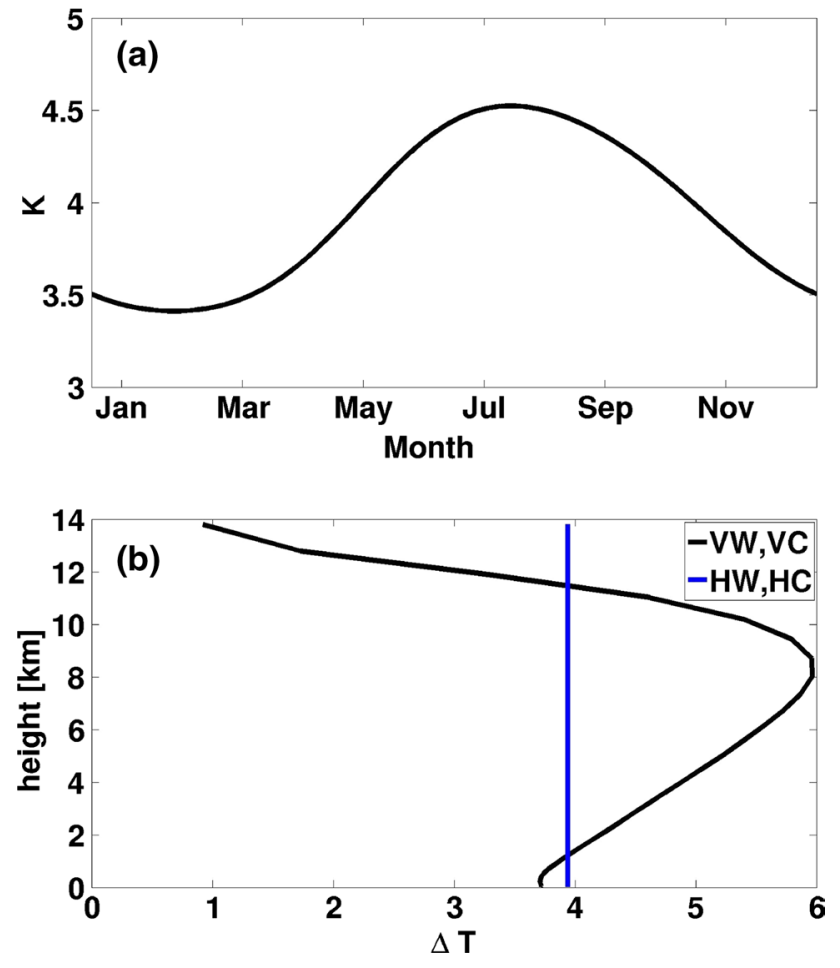

Fig. 1 a Mean annual cycle and $\mathbf{b}$ vertical structure of the warming signal SCEN-CTRL. The two cases $\Delta T=$ const and $\Delta T=\Delta T(z)$ are shown by black and blue lines, respectively

As a smoothing algorithm a spectral filter was used because of its superior performance compared to a moving mean (Bosshard et al. 2011). For $\Delta T(z)$ the smoothing was done on every level separately. On the 13 model level corresponding roughly to the $850 \mathrm{hPa}$ level the same annual cycle is used for both cases, i.e. for $\Delta T=$ const and $\Delta T=\Delta T(z)$. The horizontal averaging is performed over the whole computational domain.

In practical terms, the approach works as follows: at all grid points and levels of the atmospheric boundary data, $\Delta T$ is added and the specific moisture content is increased according to the Clausius Clapyeron relation. To maintain physical consistency also the pressure on every model level has to be adapted. This is achieved by integrating the hydrostatic balance

$\frac{d p(z)}{d z}=-g * \frac{p(z)}{R * T(z)}$

numerically from the bottom to the top of the atmosphere, using the surface pressure from the parent simulation (CTRL or SCEN, respectively).

All other variables in the lateral boundary data relaxation zone, in particular the horizontal wind, are used without changes. To keep the atmosphere at the boundaries in balance with the ocean, the sea surface temperatures (SSTs) are increased by the same $\Delta T$ as the lowest atmospheric

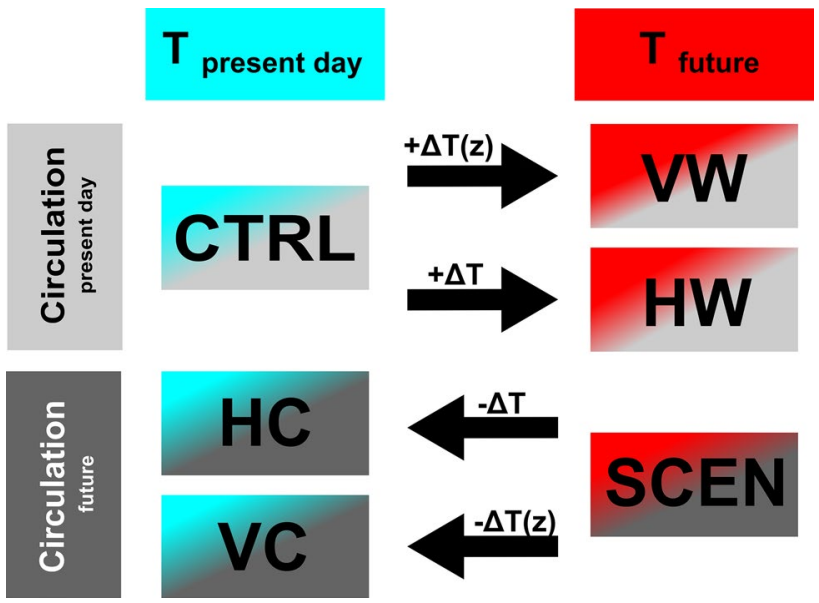

Fig. 2 Schematic of the six simulations conducted. CTRL and SCEN refer to the two reference simulations for the periods 1971-2000 and 2070-2099, respectively. The four surrogate experiments are homogeneous warming (HW), homogeneous cooling (HC), verticallydependent warming (VW) and vertically-dependent cooling (VC). Blue and red colors refer to present-day and future temperatures, respectively, whereas the grey scale encodes the state of the circulation: light gray for present-day circulation and dark grey future circulation. The arrows represent how the surrogate experiments were constructed

level. The same procedure was also applied by Schär et al. (1996) and Im et al. (2010). The soil moisture is left unchanged and can evolve freely during the simulation, as the present study was not aiming at separating the influence of soil moisture feedbacks on climate change. The atmospheric concentrations of $\mathrm{CO}_{2}$ and further greenhouse gases are taken from the driving scenario representing RCP8.5. For all simulations (CTRL, SCEN and surrogate) the aerosol climatology from Tanré et al. (1984) is used. Through this method $\Delta T$ was added to the lateral boundary conditions of the CTRL period, but also subtracted from lateral boundary conditions of the SCEN period (twin-design). This provides a future circulation in a climate with the same mean temperature as today and, hence, an independent estimate of the large-scale thermodynamic effect. A similar approach was used by ROW06 and KEN10.

The four surrogate experiments are shown in Fig. 2 and referred to as homogeneous warming (HW; applied to CTRL) and homogeneous cooling (HC; applied to SCEN) and the same for the vertically-dependent approach with vertically-dependent warming (VW; applied to CTRL) and vertically-dependent cooling (VC; applied to SCEN).

\subsection{Arithmetics of the surrogate approach}

The numerical experiments defined above enable the separation of the climate change signal into thermodynamic, lapse-rate and circulation plus other remaining effects. 
Here we provide the respective definitions. A validation of the associated interpretations will follow a posteriori.

\subsubsection{Large-scale thermodynamic effect (TD)}

This effect is meant to represent changes that are related to the large-scale homogeneous warming of the atmosphere and the accompanying increase of specific moisture, also including the direct radiative effect of future changes in $\mathrm{CO}_{2}$ and other greenhouse gases. Due to the twin design, there are two ways to quantify this effect. It can either be calculated as the difference $H W-C T R L$, or as the difference $S C E N-H C$. The temperature perturbations applied in these two experiments are the same but with opposite sign. Later we will investigate these two estimates and find that they are indeed similar. Following this reasoning, we define the thermodynamic effect as the average of the two estimates, i.e.

$T D:=\frac{(H W-C T R L)+(S C E N-H C)}{2}$

\subsubsection{Lapse-rate effect (LR)}

The lapse-rate effect is defined as the difference of the two surrogate approaches with homogeneous and verticallydependent warming or cooling. In the homogeneous surrogate experiments, the mean change in the lapse-rate is excluded, whereas it is accounted for in the verticallydependent experiments. There are again two options to diagnose the effect, either as $V W-H W$ or as $H C-V C$, and following (3) we define it as the average:

$L R:=\frac{(V W-H W)+(H C-V C)}{2}$

\subsubsection{Large-scale circulation and other remaining effects (CO)}

This effect is indirectly defined by the large-scale atmospheric and ocean features not covered in the vertically dependent surrogate experiments, i.e. as the residual between a full and a surrogate scenario. Note that thereby it is not possible to separate a circulation response to external forcing from internal variability. As above, there are two ways to calculate the $\mathrm{CO}$, and the average of the two effects is considered:

$C O:=\frac{(S C E N-V W)+(V C-C T R L)}{2}$

\subsubsection{Full climate change (FCC)}

Adding up the three contributions as defined above implies a large number of cancellations and yields:

$S C E N-C T R L=T D+L R+C O$
This is one of the key results of this study. It demonstrates that the climate change signal SCEN - CTRL as simulated in the full downscaling mode can be split into large-scale thermodynamic (TD), lapse-rate (LR), and circulation plus other remaining (CO) effects. Within the framework considered, the splitting is exact by design and does not involve any approximations. This attractive property is achieved by using both cooling and warming surrogate experiments. This set-up is responsible for the cancellations that ultimately yield the simple result (6).

It is important to note that the plausibility of the above definitions needs to be checked a posteriori. In practice we will do so by comparing the two possible definitions. For instance, the identification of $L R$ as a lapse-rate effect is only justified provided the two definitions, i.e. $V W-H W$ and $H C-V C$ yield a qualitatively similar estimate. If the two definitions were to differ substantially, it would mean that a simple additive separation into the three effects as in (6) is not feasible.

\subsection{Model and setup}

We here use the regional climate model Consortium for Small-Scale Modelling in Climate Mode (COSMO-CLM), hereafter referred to as CCLM. CCLM is a non-hydrostatic and fully-compressible regional climate model, based on the numerical weather prediction model COSMO (Baldauf et al. 2011). Here we use model version 4.8 clm17 (Rockel et al. 2008), which has also been heavily tested and applied in the framework of EURO-CORDEX. A more detailed description of the model and its parameterization schemes can be found in Vautard et al. (2013) and Kotlarski et al. (2014). We do not present a validation for our CTRL simulations, since the good performance of CCLM over the European continent was demonstrated in previous studies (Jaeger et al. 2008; Bellprat et al. 2012; Montesarchio et al. 2014; Ban et al. 2014; Kotlarski et al. 2014). The CCLM model domain corresponds to the EURO-CORDEX domain. Using a rotated latitude-longitude grid, it approximately covers the area from $27 \mathrm{~N}-72 \mathrm{~N}$, and $33 \mathrm{~W}-45 \mathrm{E}$, which covers the larger European area including the North-Atlantic, parts of Greenland and Northern Africa. The resolution is $0.44^{\circ}(50 \mathrm{~km})$.

In all experiments CCLM is driven by the global climate model (GCM) MPI-ESM-LR (Stevens et al. 2013) at the lateral boundaries. The driving GCM is forced with historical radiative forcing until 2005, and the Representative Concentration Pathway (RCP) 8.5 thereafter (Moss et al. 2010). To maximize the signal to noise ratio, our analysis focuses on the time slices 1971-2000 and 2070-2099. These 30 -year-long simulation periods are referred to as CTRL and SCEN, respectively. The two CTRL and SCEN simulations are standard CORDEX experiments and part of a transient simulation covering the time period 1950-2100. 

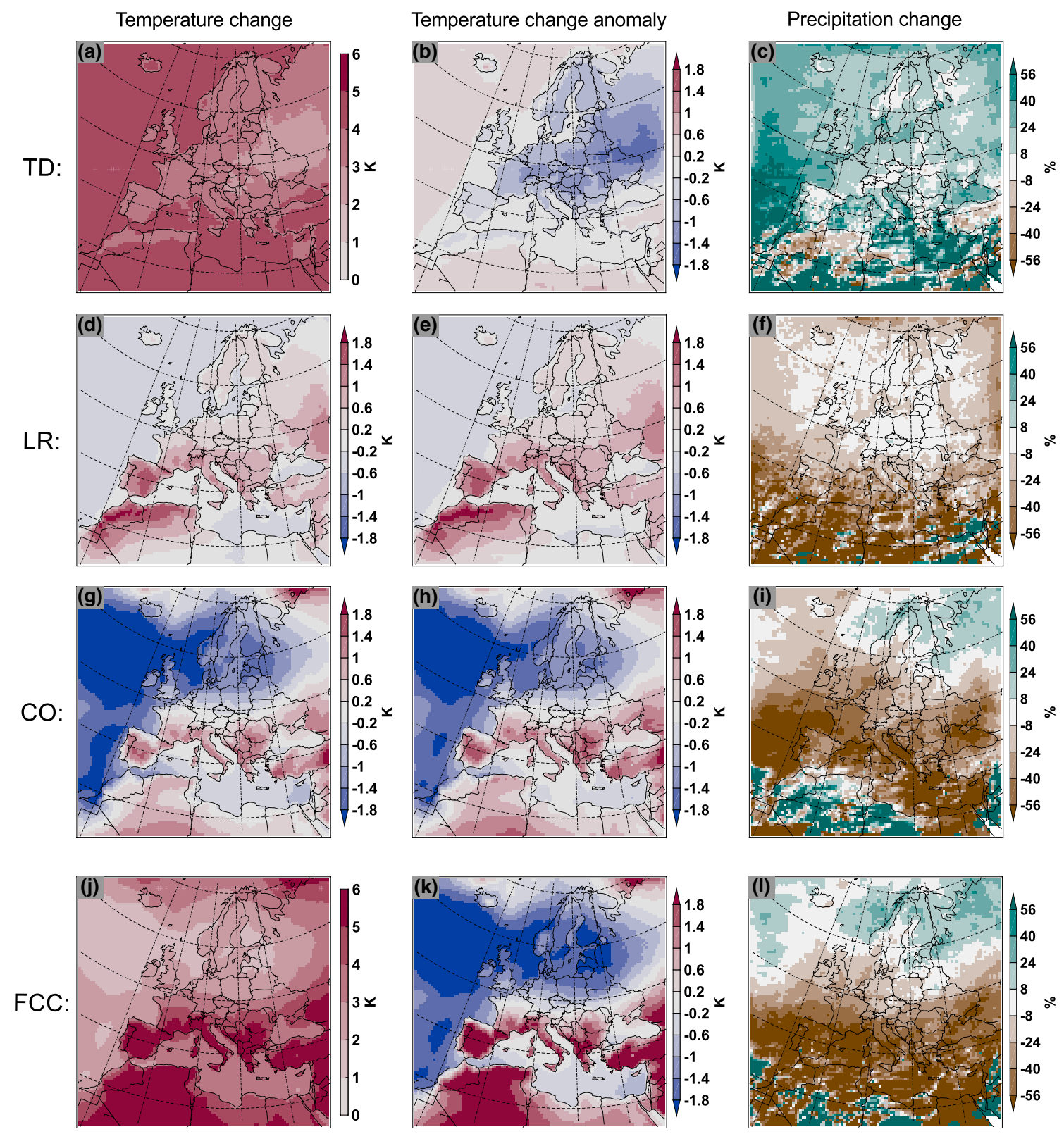

Fig. 3 Separation of the JJA climate change signal. The first three rows show a-c the large scale thermodynamic effect $(T D), \mathbf{d}-\mathbf{f}$ the lapse-rate effect $(L R)$ and $\mathbf{g}-\mathbf{i}$ the large-scale circulation plus other remaining effects $(C O)$, respectively. The fourth row shows the full climate change signal $(F C C=S C E N-C T R L)$. The left and the middle column show changes in $2 \mathrm{~m}$ seasonal mean temperature, abso- lute and as anomalies to the domain mean respectively. The right column shows relative changes in total precipitation (in the southern regions over the Sahara the absolute precipitation amounts are very low $(<0.2 \mathrm{~mm} /$ day $)$ therefore relative changes can become very high and are not robust)

\section{Results}

31-year long time slices specifically conducted for the current paper. These simulations use a modified restart file of the respective reference simulations as initial conditions. As mentioned above the soil moisture is not changed, but the soil temperatures are adjusted by a $\Delta T$ representing the actual difference between the two start dates. The first year is than used as spin up.
In the following section the influences of large-scale thermodynamic, lapse-rate and large-scale circulation changes plus other remaining changes on the mean European summer climate are presented. Figure 3 shows the main results which will be presented in the following subsections. 


\subsection{The thermodynamic effect}

The large-scale thermodynamic effect leads to a rather homogeneous warming over the European continent (Fig. 3a). Over eastern Europe the warming signal is weaker, whereas parts of northern Africa show a slightly stronger temperature increase than the domain mean (Fig. 3b). In general warming over sea surfaces reflects the prescribed boundary forcing of $4.1{ }^{\circ} \mathrm{C}$ and is stronger than over land. It seems that there is a process in place which dampens the warming applied at the boundaries over the land areas (see end of this section). Precipitation is increasing over most of Europe (Fig. 3c). The strongest increase is seen at the western boundaries and over the North Atlantic. While absolute precipitation changes over the Mediterranean are small, relative changes are substantial but somewhat poorly defined due to the small reference precipitation amounts. The large-scale precipitation increase over Europe relates to the prescribed increase of specific humidity $q$ at the lateral boundaries. The same behaviour was also found by KEN10.

The general response in the thermodynamic surrogate experiment is similar to previous experiments. Like Seneviratne et al. (2002) we see a strong increase in downward longwave radiation at the surface, which is primarily associated with the strong increase of atmospheric water vapour and increased tropospheric temperatures. Incoming surface shortwave radiation is strongly reduced due to increased cloud cover and evaporation because of higher atmospheric demand. Overall it is evident that a thermodynamic change of the atmosphere alone cannot reproduce the distinct change patterns of the reference scenario (Fig. 3j-1). There is no summer drying in southern Europe, and no northsouth gradient in temperature change (Fig. 3a-c). Thus the distinct spatial patterns projected in the full climate change scenario must be caused by other mechanisms, such as large-scale circulation changes, lapse-rate changes, and/or effects due to land-ocean contrast. The TD effect also contains the influence of changes in $\mathrm{CO}_{2}$ and other greenhouse gas concentrations the influence of these changes is discussed in Sect. 4.3.

For the TD effect the imposed temperature change signal is obviously dampened over the continent (Fig. 3b). The responsible process can be identified by looking at the vertical change profile which is prescribed at the boundaries in comparison to the one simulated in the model domain. Figure $4 a-c$ show that the vertically homogeneous change profile is not preserved in the domain but also tends to become stratified with a stronger warming higher up and a weaker warming at the ground. Only profiles for the regions Mid-Europe (ME), Eastern Europe (EA) and France (FR) (see e.g. Christensen and Christensen 2007) are shown but this result is also true for the other regions. The stratification increase can be explained by a strong increase in convective activity for the TD which leads to an increase of latent heating in the higher troposphere and a cooling at the ground. Figure $4 \mathrm{~d}$ shows that the share of convective precipitation on total precipitation increases strongly.

\subsection{The lapse-rate effect}

Comparing the results of the vertically homogeneous and the vertically dependent surrogate experiments (see Eq. 4) allows us to quantify the effect of a lapse-rate change on future temperature (Fig. 3d, e) and precipitation (Fig. 3f) changes, respectively. The results will also be compared with the results of ROW06 and KEN10, who also used a vertically-dependent surrogate approach. The temperature change pattern shows a clear north-south gradient with an amplified warming in the Mediterranean region and eastern Europe. ROW06 found a similar pattern with an amplification of the warming in the Mediterranean region. In our case the amplification is especially strong over the Iberian Peninsula and western North Africa around the Atlas mountains (Fig. 3e). The simulated temperature change also exhibits some land-sea contrast, which is mainly caused by differences in the prescribed atmospheric and sea-surface $\Delta T$ (Fig. $3 \mathrm{~d}$, e). Recall that the SSTs have the same $\Delta T$ as the lowest atmospheric level and that the homogeneous and vertically dependent experiments have a different warming at these levels (Fig. 1b).

Also the precipitation signal shows a distinct north-south gradient (Fig. 3f). Unlike the thermodynamic response $T D$ which showed precipitation increases almost throughout the domain, the lapse-rate effect causes a reduction in precipitation over most of Europe, and in particular over the Mediterranean. The Mediterranean drying is further associated with a decrease in soil moisture and evaporative fraction, along with reduced cloud cover and increased short wave radiation for the warming regions (not shown). In comparison to ROW06 and KEN10 the amplitude of the precipitation decrease over continental Europe $(41 \mathrm{~N}-50 \mathrm{~N}$, 0E-31E) is much weaker. ROW06 estimated that their warming effect (which includes also some circulation effects and the lapse-rate changes) accounts for $42.5 \%$ of the precipitation decrease seen in the full climate change signal for this area. Over the same area the lapse-rate effect in our experiments accounts for $12.5 \%$ of the precipitation decrease.

Overall the results show that the lapse-rate effect can reproduce parts of the distinct change pattern as projected by the full climate change simulations. In particular, a 


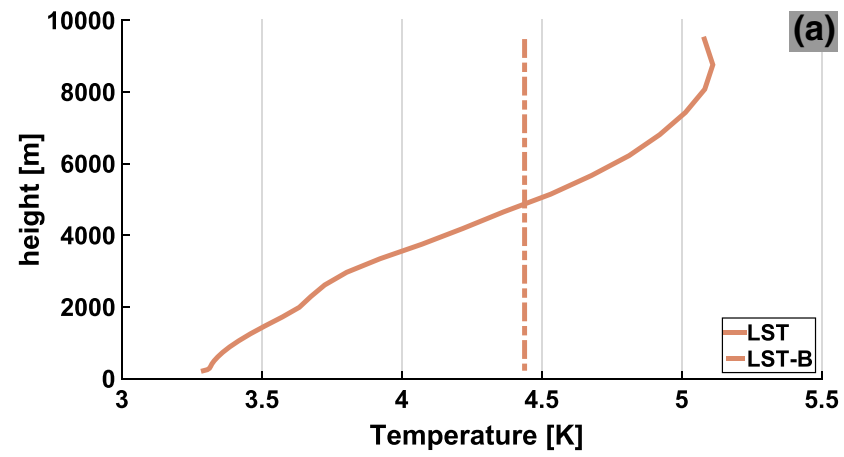

(a)

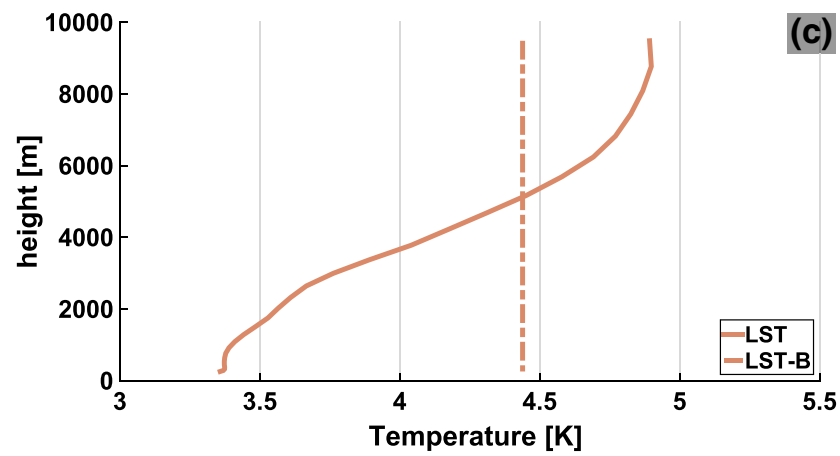

Fig. 4 TD effect on convective precipitation. a-c Vertical profile of temperature change for a Mid-Europe (ME), b Eastern Europe (EA) and c France (FR) (see e.g. Christensen and Christensen 2007). The solid line represents the actual temperature change simulated over the region, the dashed line represents the change profile prescribed at the lateral boundaries in the homogeneous warming case, $\mathbf{d}$ rela-

north-south temperature change gradient is simulated, which accounts for about $30 \%$ of the total change in gradient. Over the Iberian peninsula the lapse-rate effect accounts for more than half of the warming seen in the full climate change signal (Fig. 3j). This shows that lapse-rate changes can significantly alter the climate change signal over Europe.

\subsection{The circulation and other remaining effects}

The combined effect of the large-scale circulation change and other remaining changes is shown in Fig. $3 \mathrm{~g}-\mathrm{i}$. The temperature changes show a strong land-ocean contrast as well as a strong north-south gradient. The Atlantic, especially in the north, shows a weaker warming than the Mediterranean. This SST pattern is part of CO by design. The Mediterranean land areas show a clear amplification of the warming. Part of this warming amplification reflects the northward shift of the storm tracks predicted by most GCMs (Collins et al. 2013), which brings warmer air to southern Europe. Also precipitation changes show a distinct north-south pattern. The general effect of $\mathrm{CO}$ is a decrease in precipitation over most of Europe, with strong
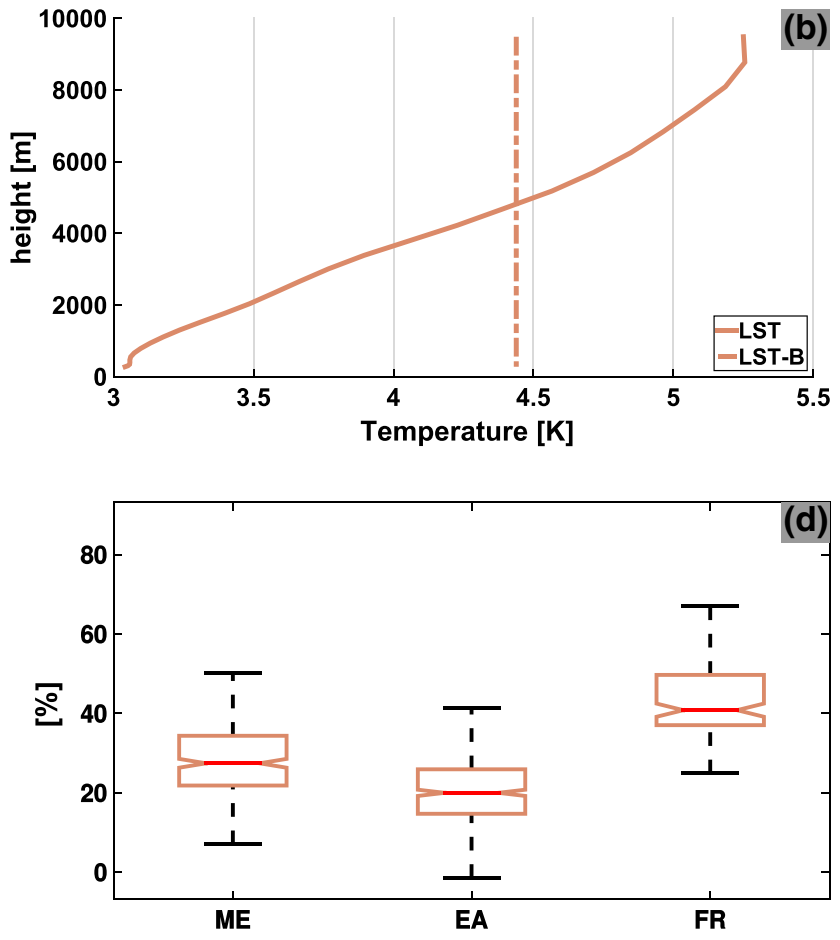

tive change in the ratio of convective to grid scale precipitation in comparison to CTRL for the same three regions ME, EA and FR. The mean change in the region is shown as red line, the spatial variability is represented, by the boxes containing all values between the 0.25 and 0.75 percentile and by the whiskers containing all values between 0.05 and 0.95 percentile

reductions in southern Europe and slight increases in Scandinavia (Fig. 3i). ROW06 and KEN10 isolated a Europeanscale reduction in precipitation due to circulation changes. For continental Europe they report circulation changes accounting for less than $10 \%$ of the precipitation decrease. We find that the combined effect of changes in circulation and the land-ocean contrast accounts for more than $80 \%$ of the full change. The difference between the two studies highlights an important role of the modified land-ocean contrast: Because the Atlantic warms substantially slower than the continent, air that is advected from sea to land experiences considerable warming and drying. This process evidently explains a significant fraction of the reduction in southern European precipitation.

\subsection{Verification of the approach}

The applied surrogate approach relies on two main assumptions, which need to be verified. First, the approach assumes that the changes in the boundary conditions are imposed onto the RCM in such a way that the large-scale circulation does not significantly change. In Fig. $5 \mathrm{~b}$ it can be seen that the differences in the mean geopotential height 

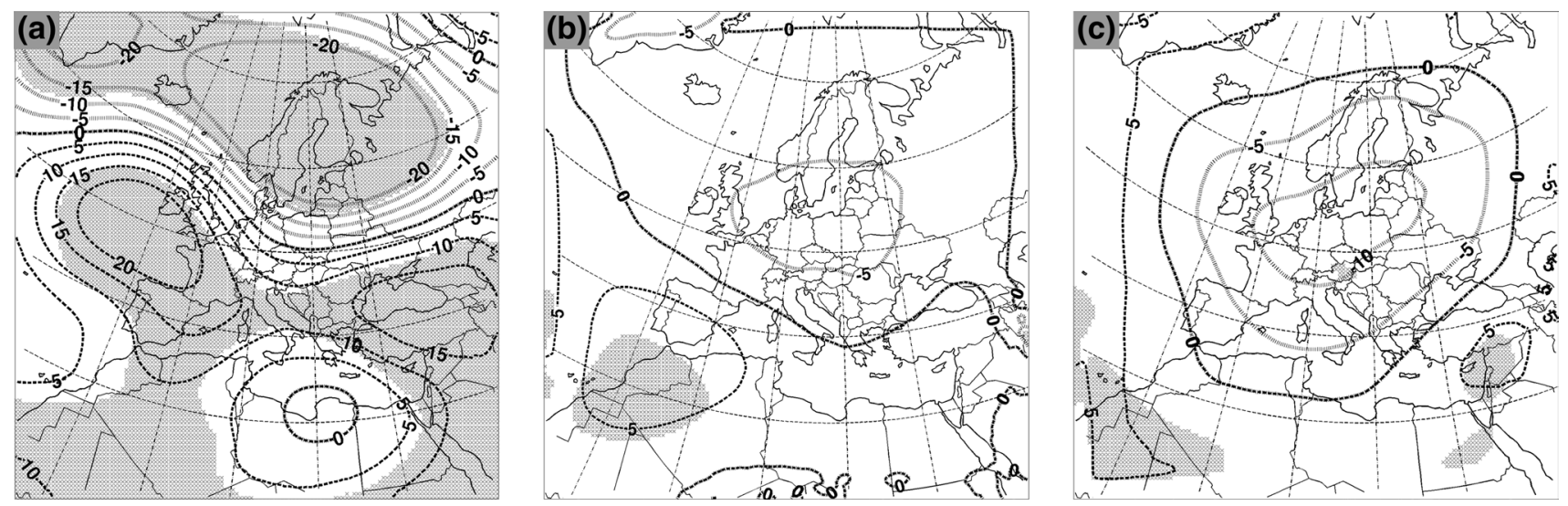

Fig. 5 Differences in $500 \mathrm{hPa}$ geopotential height anomalies; Gridpoints where the difference is significant at the $5 \%$ level are shaded. a SCEN-CTRL, b VW-CTRL and $\mathbf{c}$ HW-CTRL

at $500 \mathrm{hPa}$ are small between the VW experiment and its reference simulation CTRL, and the same is true for the HW experiment (Fig. 5c). The change from CTRL to the future circulation of SCEN is much stronger (Fig. 5a). In Fig. 5 a $50 \%$ of the points show a significant difference, whereas in Fig. 5b-c only around $5 \%$ of the points are significant. In addition, the differences in Fig. 5b, c exhibit a large-scale pattern that can be linked to large-scale differences in low-level atmospheric temperature. This is also true for the difference in mean geopotential height between SCEN and the cooling surrogate experiments $\mathrm{HC}$ and VC (not shown). These results suggest that the large-scale circulation is only slightly altered by the thermodynamic changes to the boundaries. It confirms our assumption of largely unchanged flow condition between references simulation and surrogate experiment.

Second, the surrogate approach assumes that TD, LR and $\mathrm{CO}$ are separable and no important interactions occur. Note, however, that the averaged terms of the twin design (Eqs. 3-5) cannot be used to verify this assumption, as combining these equations exactly yields the SCEN-CTRL climate change signal by design. As mentioned in Sect. 2.3 there is another way to verify the approach: The two possibilities to quantify each individual effect should lead to similar results, that is:

$T D \approx H W-C T R L \approx S C E N-H C$

$L R \approx V W-H W \approx H C-V C$

$C O \approx S C E N-V W \approx V C-C T R L$

Figure 6) shows both options of (7-9) for $2 \mathrm{~m}$ temperatures, and Fig. 7) for precipitation changes. For temperature the spatial change patterns are very similar (spatial correlation of at least 0.95 ) but the amplitude differs slightly (Fig. 6). Over most parts of Europe the lapse-rate effect is stronger
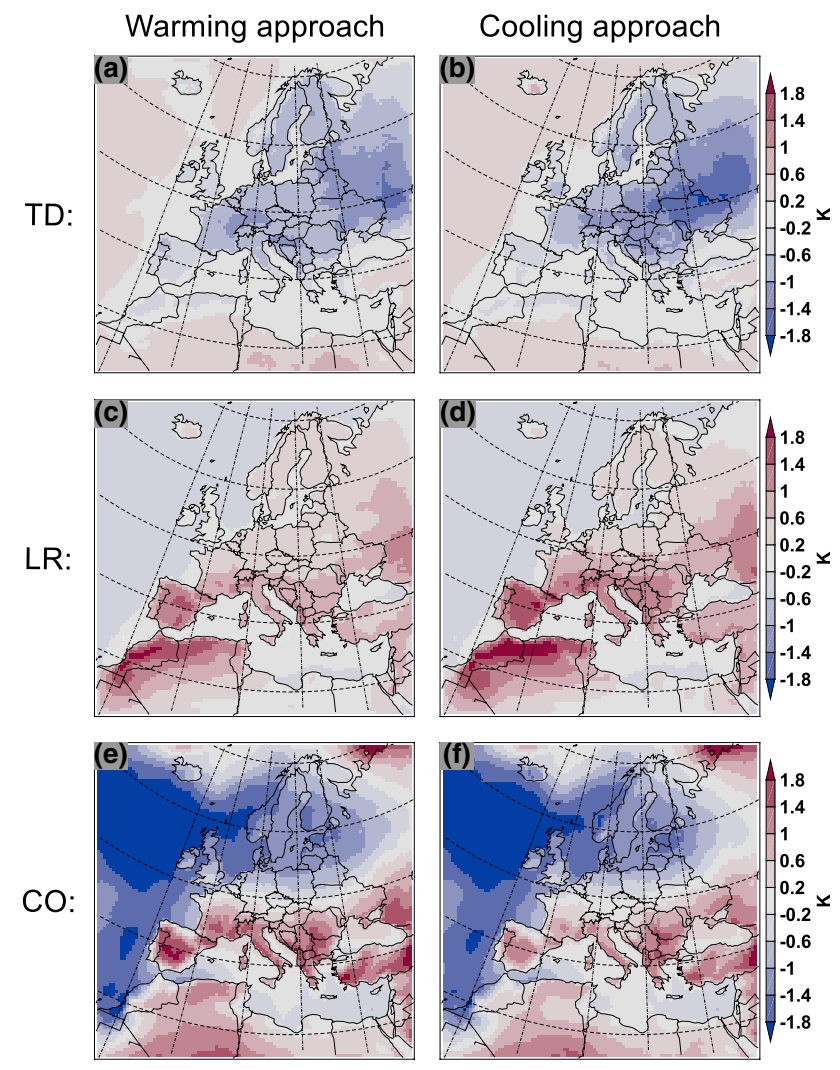

Fig. 6 Changes in $2 \mathrm{~m}$ temperature for JJA; the two columns represent the two different ways to calculate the different effects according to (7-9). The first row shows the thermodynamic effect (as anomalies to the domain mean change) as a HW-CTRL and b SCEN-HC, the second row the lapse-rate effect as $\mathbf{c} \mathrm{VW}-\mathrm{HW}$ and $\mathbf{d} \mathrm{HC}-\mathrm{VC}$, and the third row the large-scale circulation plus other remaining effects as $\mathbf{e}$ SCEN-VW and $\mathbf{f}$ VC-CTRL

for HC-VC in comparison to VW-HW (Fig. 6c, d), suggesting that the lapse-rate effect is stronger for a future circulation. For total precipitation the spatial correlation is 

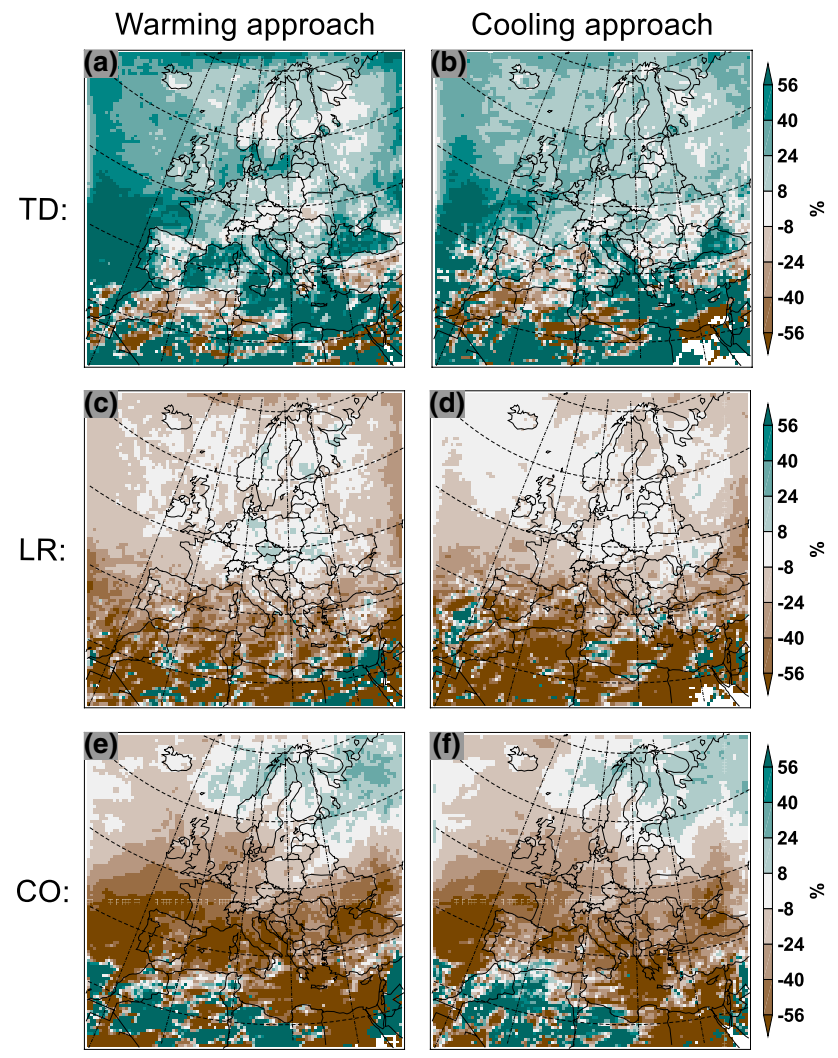

Fig. 7 Same as in Fig. 6, but for relative changes in precipitation

smaller but still acceptable (at least 0.85) (Fig. 7). In general the analysis yields a good agreement between the two ways of quantifying the three effects. This is true for JJA, but also for the other seasons (not shown). These results indicate that interactions are overall too weak to distort the separation of the effects with the surrogate method, and that the method-as such—is well applicable.

\section{Discussion and further analysis}

\subsection{Interpretation of the lapse-rate effect and the Mediterranean warming amplification}

Concerning the amplification of the warming in the Mediterranean region, ROW06 found a similar pattern as in the current study (Fig. 3d). They argue that the extra warming over the Mediterranean is caused by less advection of cold maritime air, which increases the influence of radiative effects. In our study we see a similar behaviour, but we can attribute these changes to the lapse-rate effect, which was implicitly also included by ROW06.

The role of the lapse-rate effect is consistent with the existing literature. It is well understood that the projected large-scale warming and moistening will lead to increases in the moist-adiabatic lapse rate, which in turn implies changes in stratification. This is critical as theoretical and modelling studies suggest that large-scale stratification determines the extent of the Hadley circulation. In particular the Hadley circulation is believed to extend polewards up to the latitude where the vertical shear becomes baroclinically unstable ( $\mathrm{Lu}$ et al. 2007; Levine and Schneider 2015), and thus is expected to expand in response to increasing stratification and an increasing depth of the extratropical troposphere. As a result of the extension, the Mediterranean and southern Europe would become more strongly affected by subsidence in the descending branch of the Hadley circulation, which would tend to suppress convection and lead to less precipitation, stronger inversions, and warmer surface temperatures (in response to decreased vertical exchange).

Studies in the literature also show that there is a further amplification by positive feedbacks that involve reduced relative humidity, decreased cloud cover, increased incoming short-wave radiation, ampflified subsidence, and reduced soil moisture.

The role of the ensuing feedback processes is apparent from studies of European heat waves. In particular, the linkage between soil moisture deficits and heatwaves has been well established (e.g. Fischer et al. 2007), and also a strengthening of inversions due to increased subsidence has been documented (Miralles et al. 2014). The current study includes these amplification effects and raises attention to the role of lapse-rate changes, but we do not attempt to quantify the ensuing feedback processes.

Overall our results show that including the lapse-rate change into the thermodynamic effect more realistically replicates the behaviour seen in scenario simulations. For further surrogate experiments it is hence an important decision whether to include the lapse-rate change or not.

In the next subsections we provide further analysis and investigate additional factors that may contribute to the Mediterranean drying.

\subsection{Mediterranean drying and the land-ocean contrast}

In Sect. 3.2 it was shown that the lapse-rate effect yields a distinct drying and warming pattern over the Mediterranean. We define the Mediterranean area to include the two regions Iberian Peninsula (IP) and Mediterranean (MD) (see Christensen and Christensen 2007). When comparing our results to existing studies, certain differences are found that partly relate to the setup. ROW06 and KEN10 identified, what they call the thermodynamic effect to be dominating the Mediterranean summer drying. In contrast we identified the large-scale circulation plus other remaining effects to be the dominating factor (Fig. 3i). A fully quantitative comparison is not possible as no domain averages 
are given by ROW06 and KEN10 beside for an area in continental Europe by ROW06 and we are restricted to qualitatively compare area plots. As alluded to above, beside similarities in the design (all three studies use a vertically dependent $\Delta T$ ), there are also important differences in the surrogate setup, regarding how the lateral and lower boundary conditions are imposed. In the design of ROW06 and KEN10, changes in land-ocean temperature contrast as well as horizontal temperature gradients were included into the large-scale thermodynamic change effect. The SSTs in the surrogate experiment where taken from the scenario and $\Delta T$ was not just a function of height but also of longitude and latitude $\Delta T(x, y, z)$. In the present study the landsea contrast as well as the horizontal temperature gradient are not included in the large-scale thermodynamic effect. $\Delta T$ is a function of height only and the SSTs are raised by the same amount as the temperature on the lowest atmospheric level.

Especially the difference in the treatment of the landocean warming contrast appears important. In the literature there is a growing number of studies which argue that the land-ocean warming contrast has an important contribution to the projected Mediterranean drying (Fasullo 2010; Boe and Terray 2014; Sherwood and Fu 2014). The differences between the present study and ROW06 and KEN10 do not contradict this hypothesis. In the present work the landocean warming contrast is not included in the large-scale thermodynamic effect (TD), and as a consequence the associated Mediterranean drying is much weaker than in the study of ROW06 and KEN10, who included this feature in their thermodynamic effect. In the present study the landocean warming contrast is part of the large-scale circulation and other remaining effects (CO). Hence the associated simulations show a strong drying over the Mediterranean as well as the Central European region (Fig. 3i). This confirms that the land-ocean warming contrast is likely an important factor for the Mediterranean drying. The question remains whether the general land-ocean warming contrast or the specific geographical pattern of SST changes (less warming in the North Atlantic and stronger warming in the Mediterranean) is the more important factor.

To investigate this question, two additional surrogate experiments were carried out. One is based on the VW experiment (VW_SST) one on the VC experiment (VC_ SST). In these experiments the SSTs are not increased/ decreased by the same amount as the lowest atmospheric level, but by the domain mean SST difference between SCEN and CTRL. This translates to a $\sim 1 \mathrm{~K}$ smaller SST increase/decrease for JJA and a stronger land-ocean warming contrast. The lateral boundary variables are exactly the same as in VW or VC respectively. With those two additional surrogate experiments the effect of a mean
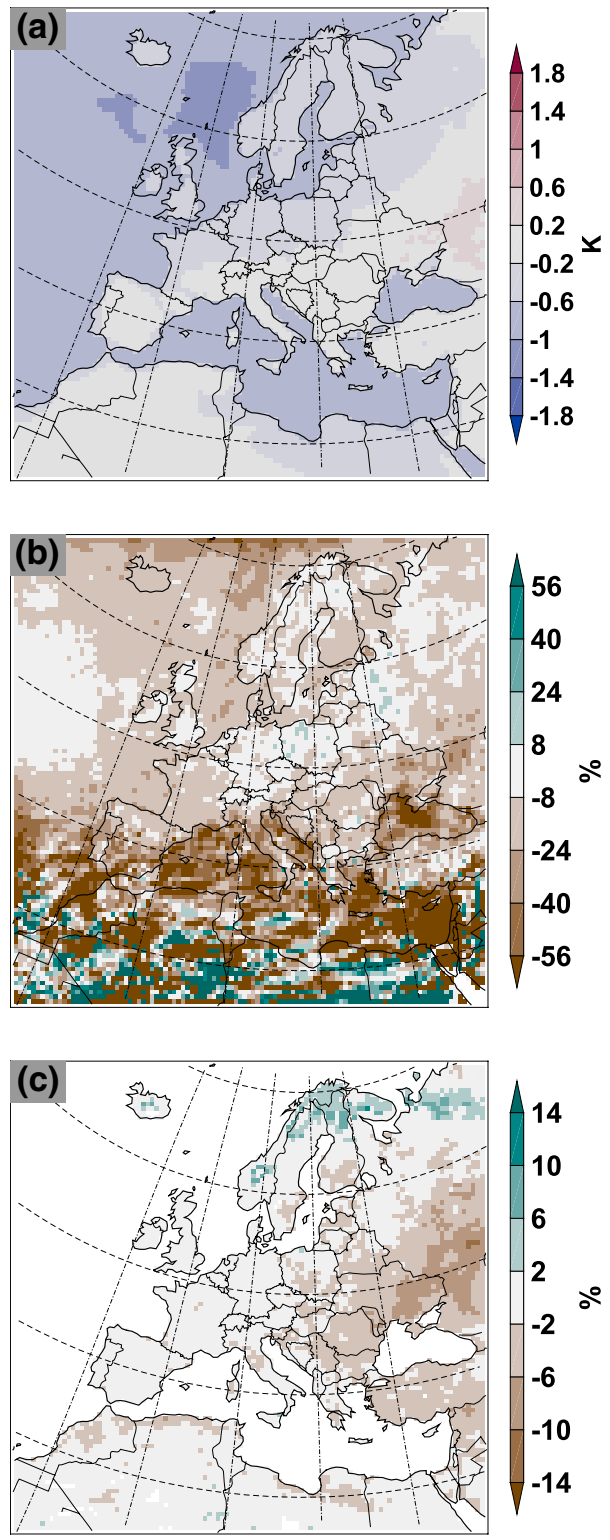

Fig. 8 Effect of the land-ocean contrast (LOC) on a $2 \mathrm{~m}$ temperature, b total precipitation (\%) and c soil moisture (\%). Soil moisture integrated over the seven topmost layers (corresponding to the top $1.5 \mathrm{~m}$ of the soil)

land-ocean contrast (LOC) can be calculated in the same fashion as the other three effects:

$L O C:=\frac{\left(V W \_S S T-V W\right)+\left(V C-V C \_S S T\right)}{2}$

Figure 8 shows that the LOC is mainly decreasing temperature through out the domain but has almost no influence on the spatial change pattern and can not explain the Mediterranean warming amplification. In contrast to temperature the influence on precipitation especially over the 
Mediterranean is stronger although not as strong as for the lapse-rate effect. Nevertheless one can conclude that the mean land-ocean contrast contributes to the Mediterranean drying. We argued before that the land-ocean contrast could explain part of the contrasting results between our study and ROW06 but the question remains whether the general land-ocean warming (tested in Fig. 8) or spatial SST changes are more important. The presented results suggests that the spatial change pattern in the SST (i.e. the warming minima over the North Atlantic) makes an important contribution to the Mediterranean drying. However, the influence of these changes is more difficult to quantify because they are coupled to changes in the atmospheric circulation via the thermal wind relation.

Another important conceptual difference in the setup concerns soil moisture effects. ROW06 and KEN10 conducted specific experiments to test the role of spring and summer soil moisture feedbacks. In those experiments they showed that soil moisture changes are a significant component of the reduction in summer precipitation. We did not conduct such experiments, but use the soil-moisture to diagnose the Mediterranean drying. To this end, Fig. 9 shows the JJA soil moisture signal for our experiments. The figure shows that most of the summer soil moisture change shows up in the large-scale circulation and other remaining effects (CO), with some minor imprints also in the lapserate experiment (LR). This shows that in our setting the soil moisture effect on summer drying is implicitly included in the $\mathrm{CO}$ effect. Note that additional experiment would be needed to further disentangle the regional feedbacks caused by the $\mathrm{CO}$ effect.

\subsection{Role of greenhouse gases}

The TD effect also contains the influence of changes in $\mathrm{CO}_{2}$ and other greenhouse gas concentrations following the RCP8.5 scenario. To quantify the influence of these concentration changes we performed an additional vertical warming experiment (VW_GHG) in which atmospheric greenhouse gas concentrations are prescribed according to the CTRL simulation. Influence of $\mathrm{CO}_{2}$ and other greenhouse gases is than calculated as the difference between VW and (VW_GHG). Figure 10 shows that the influence of these changes on our regional climate simulation are very weak. These results confirm the findings of earlier surrogate experiments (Seneviratne et al. 2002).

\subsection{Assessing projection uncertainties}

Projected changes in the atmospheric circulation in response to greenhouse gas forcing are considered rather uncertain (Christensen et al. 2013; Shepherd 2014; Hall 2014). Therefore the discrimination between

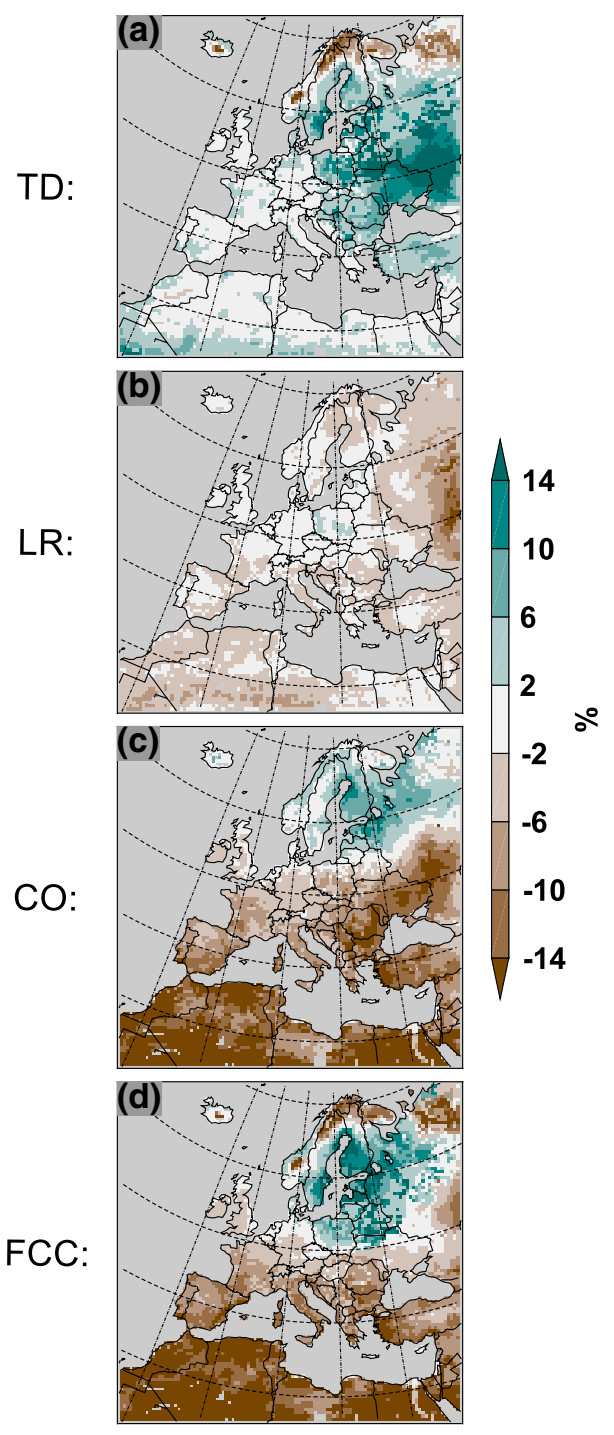

Fig. 9 Same as in Fig. 3, but for relative changes in soil moisture integrated over the seven topmost layers (corresponding to the top $1.5 \mathrm{~m}$ of the soil)

thermodynamic and dynamic effects is often used to discriminate between more and less reliable aspects of the projections.

The surrogate approach offers a direct possibility to address this discrimination in comparison to other more statistical analyses, such as studies using climate analogues (Cattiaux et al. 2013). The surrogate approach provides an opportunity to separate thermodynamic (TD), lapse-rate (LR) and circulation plus other remaining (CO) effects, and thereby assess projection uncertainties in climate change scenarios. A problem of this approach is that the $\mathrm{CO}$ effect combines effects with different associated uncertainties, the two most important are the large-scale circulation changes and the land-ocean contrast. The change in large-scale circulation as already mentioned above is regarded as rather 

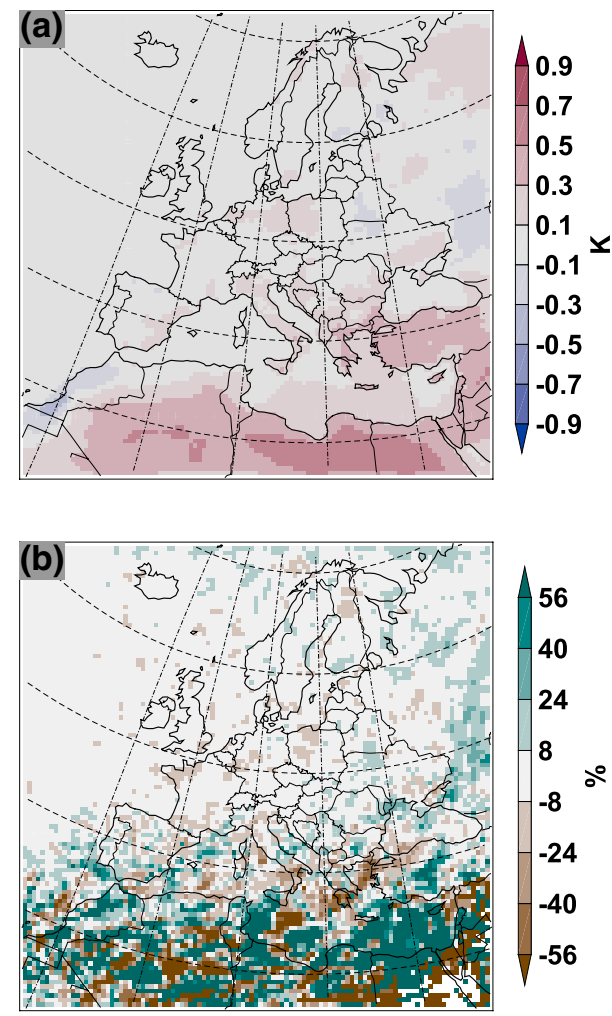

Fig. 10 Effect of $\mathrm{CO}_{2}$ and other greenhouses gas concentrations on surrogate simulations for the summer season JJA. Calculated as the difference between the vertical warming experiment (VW) with a greenhouse gas forcing according to the RCP8.5 scenario and a VW experiment with historical greenhouse gas forcing. a $2 \mathrm{~m}$ temperature and $\mathbf{b}$ total precipitation \%. Note that (a) uses a finer color scale than other figures

uncertain, whereas the general land-ocean warming contrast is a very robust feature of climate change projections (Joshi et al. 2008; Lambert et al. 2011). However, in section 4.2 we show that the general land-ocean contrast is not such an important driver which suggests that the spatial change pattern in the SST is very important and this pattern as well as the associated circulation changes are more uncertain. These arguments justify to assess the CO effect as more uncertain than the TD and LR effects.

Our results (see Fig. 3) show that the general warming is driven primarily by thermodynamic effects (TD). Still large parts of the spatial temperature change pattern are strongly influenced by the $\mathrm{CO}$ and the LR.

Following the argumentation of Hawkins and Sutton (2011) and Shepherd (2014), precipitation is strongly influenced by dynamic and thermodynamic effects, and the dependence upon dynamic effects thus implies considerable uncertainties. Studies of large ensembles, for example Cattiaux et al. (2013), show that the precipitation signal for the summer season over mid Europe is strongly depending on the GCM considered. The transition line between precipitation increases in the north and decreases in the south depends significantly on the selected model.

Our study indicates that this uncertainty in response pattern of precipitation results from the opposing influence of thermodynamic, lapse-rate and dynamic effects. In Northern Europe, TD and CO effects lead to an increase in precipitation, while in southern Europe LR and CO (and to a lesser extent TD) effects lead to a precipitation decrease, whereas in Central Europe TD and CO have opposing signs. Our study adds LR effects to this discussion. In particular, we consider the LR effects as less uncertain than the $\mathrm{CO}$ effects, as the temperature-dependence of the moist adiabatic lapse-rate can be considered a fundamental property. That said, we are not aware of a detailed analysis of changes in lapse-rates over Europe in the CMIP5 ensemble.

\subsection{Limitations}

Our study has a number of limitations. First of all, we considered only one realization of one RCM and its driving GCM. To some extent this limitation is counteracted by the special twin-design, which allows assessing the robustness of the effects relative to two different background circulations. In addition, we did not aim at separating the largescale circulation changes in a forced response of circulation and internal variability. Internal variability has been found to play an important role for trends in circulation even at multi-decadal time scales. Note however, that the role of internal variability is particularly dominant in near-term climate change whereas we here look at long-term changes by the end of the century (Hawkins and Sutton 2011).

\section{Conclusions and outlook}

In this study the surrogate (or pseudo-warming) approach was extended in a European-scale study. The primary research question was to quantify the contributions of large-scale thermodynamic, lapse-rate and dynamical changes to the European summer climate.

We have applied both warming and cooling profiles to the CTRL and SCEN simulations, respectively. Results show that this twin design allows for a clear separation of three main effects: large-scale thermodynamic, lapserate and dynamical effects. More specifically, we find that applying a warming to CTRL has a similar effect as applying a cooling to SCEN. This demonstrates that the basic response to large-scale climate changes is not overly dependent upon the reference climatology.

We find that the thermodynamic effect alone, which manifests itself in an overall warmer and moister summer climate, cannot reproduce the typical north-south warming gradient and Mediterranean drying of climate simulations. 
When accounting for a lapse-rate change some fraction of the typical southern European summer drying and amplified warming can be reproduced, even though the prescribed lapse-rate change is horizontally homogeneous. About half of the amplified warming over the Iberian Peninsula can be explained by the lapse-rate effect. The influence of the lapse-rate effect is linked to an extending Hadley circulation. Large-scale circulation changes and other remaining effects make a further important contribution to the Mediterranean amplification, i.e. they amplify the warming and drying over southern Europe.

After establishing the current methodology for mean climate changes, it would be of interest to consider changes in temperature variability and climate extremes. Especially for those phenomena, the possibility to disentangle thermodynamic, lapse-rate and dynamic effects could give valuable insights into the processes dominating the changes in higher order statistics. For a better estimate of the reliability of the described effects, a similar study with a different RCM would be very helpful.

Acknowledgments The COSMO-CLM simulations studied in this work were carried out at the Swiss National Supercomputing Centre (CSCS). We are thankful to the COSMO and CLM communities who maintain and develop the model. We also want to acknowledge the work of Stauffer et al. (2015) who provided the tool to generate the applied colour scale. We thank Tapio Schneider for his helpful comments on this work and its relation to the Hadley circulation. We also want to thank the two anonymous reviewers for their constructive and useful comments.

Open Access This article is distributed under the terms of the Creative Commons Attribution 4.0 International License (http://creativecommons.org/licenses/by/4.0/), which permits unrestricted use, distribution, and reproduction in any medium, provided you give appropriate credit to the original author(s) and the source, provide a link to the Creative Commons license, and indicate if changes were made.

\section{References}

Allen M, Ingram W (2002) Constraints on future changes in climate and the hydrologic cycle. Nature 419:224+. doi:10.1038/ nature 01092

Baldauf M, Seifert A, Foerstner J, Majewski D, Raschendorfer M, Reinhardt T (2011) Operational convective-scale numerical weather prediction with the COSMO model: description and sensitivities. Mon Weather Rev 139:3887-3905. doi:10.1175/ MWR-D-10-05013.1

Ban N, Schmidli J, Schaer C (2014) Evaluation of the convectionresolving regional climate modeling approach in decade-long simulations. J Geophys Res Atmos. doi:10.1002/2014JD021478

Ban N, Schmidli J, Schaer C (2015) Heavy precipitation in a changing climate: does short-term summer precipitation increase faster? Geophys Res Lett 42:1165-1172. doi:10.1002/2014GL062588

Barnes EA, Polvani L (2013) Response of the midlatitude jets, and of their variability, to increased greenhouse gases in the CMIP5 models. J Clim 26:7117-7135. doi:10.1175/JCLI-D-12-00536.1
Barriopedro D, Fischer EM, Luterbacher J, Trigo R, Garcia-Herrera R (2011) The hot summer of 2010: redrawing the temperature record map of Europe. Science 332:220-224. doi:10.1126/ science. 1201224

Bellprat O, Kotlarski S, Luethi D, Schaer C (2012) Exploring perturbed physics ensembles in a regional climate model. J Clim 25:4582-4599. doi:10.1175/JCLI-D-11-00275.1

Boe J, Terray L (2014) Land-sea contrast, soil-atmosphere and cloudtemperature interactions: interplays and roles in future summer European climate change. Clim Dyn 42:683-699. doi:10.1007/ s00382-013-1868-8

Bony S, Colman R, Kattsov VM, Allan RP, Bretherton CS, Dufresne J-L, Hall A, Hallegatte S, Holland MM, Ingram W, Randall DA, Soden BJ, Tselioudis G, Webb MJ (2006) How well do we understand and evaluate climate change feedback processes? J Clim 19:3445-3482. doi:10.1175/JCLI3819.1

Bosshard T, Kotlarski S, Ewen T, Schär C (2011) Spectral representation of the annual cycle in the climate change signal. Hydrol Earth Syst Sci 15:2777-2788. doi:10.5194/hess-15-2777-2011

Cattiaux J, Douville H, Peings Y (2013) European temperatures in CMIP5: origins of present-day biases and future uncertainties. Clim Dyn 41:2889-2907. doi:10.1007/s00382-013-1731-y

Cattiaux J, Douville H, Schoetter R, Parey S, Yiou P (2015) Projected increase in diurnal and interdiurnal variations of European summer temperatures. Geophys Res Lett 42:899-907. doi:10.1002/2 014GL062531

Cess R, Potter G, Blanchet J, Boer G, Delgenio A, Deque M, Dymnikov V, Galin V, Gates W, Ghan S, Kiehl J, Lacis A, Letreut H, Li Z, Liang X, Mcavaney B, Meleshko V, Mitchel J, Morcrette J, Randall D, Rikus L, Roeckner E, Royer J, Schlese U, Sheinin D, Slingo A, Sokolov A, Taylor K, Washington W, Wetherald R, Yagai I, Zhang M (1990) intercomparison and interpretation of climate feedback processes in 19 atmospheric general-circulation models. J Geophys Res Atmos 95:16601-16615. doi:10.1029/ JD095iD10p16601

Christensen J, Krishna Kumar K, Aldrian E, An S-I, Cavalcanti I, de Castro M, Dong W, Goswami P, Hall A, Kanyanga J, Kitoh A, Kossin J, Lau N-C, Renwick J, Stephenson D, Xie S-P, Zhou T (2013) Climate phenomena and their relevance for future regional climate change, section 14. Cambridge University Press, Cambridge

Christensen JH, Christensen OB (2007) A summary of the PRUDENCE model projections of changes in European climate by the end of this century. Clim Change 81:7-30. doi:10.1007/ s10584-006-9210-7

Collins M, Knutti R, Arblaster J, Dufresne J-L, Fichefet T, Friedlingstein P, Gao X, Gutowski W, Johns T, Krinner G, Shongwe M, Tebaldi C, Weaver A, Wehner M (2013) Long-term climate change: projections, commitments and irreversibility, section 12. Cambridge University Press, Cambridge

DelGenio A, Lacis A, Ruedy R (1991) Simulation of the effect of a warmer climate on atmospheric humidity. Nature 351:382-385

Della-Marta PM, Haylock MR, Luterbacher J, Wanner H (2007) Doubled length of western European summer heat waves since 1880. J Geophys Res Atmos. doi:10.1029/2007JD008510

Fasullo JT (2010) Robust land-ocean contrasts in energy and water cycle feedbacks. J Clim 23:4677-4693. doi:10.1175/2010J CLI3451.1

Field C, Barros V, Stocker T, Qin D, Dokken D, Ebi K, Mastrandrea M, Mach K, Plattner G-K, Allen S, Tignor M, Midgley P (2012) Managing the risks of extreme events and disasters to advance climate change adaptation. Technical report, IPCC

Fischer EM, Seneviratne SI, Vidale PL, Luethi D, Schär C (2007) Soil moisture-atmosphere interactions during the 2003 European summer heat wave. J Clim 20:5081-5099. doi:10.1175/ JCLI4288.1 
Fischer EM, Rajczak J, Schär C (2012) Changes in European summer temperature variability revisited. Geophys Res Lett. doi:10.1029/ 2012GL052730

Fischer EM, Schär C (2009) Future changes in daily summer temperature variability: driving processes and role for temperature extremes. Clim Dyn 33:917-935. doi:10.1007/s00382-008-0473-8

Fischer E, Schär C (2010) Consistent geographical patterns of changes in high-impact European heatwaves. Nat Geosci 3:398 403. doi:10.1038/NGEO866

Frei C, Schär C, Luthi D, Davies H (1998) Heavy precipitation processes in a warmer climate. Geophys Res Lett 25:1431-1434. doi:10.1029/98GL51099

Gregory J, Mitchell J, Brady A (1997) Summer drought in northern midlatitudes in a time-dependent $\mathrm{CO}_{2}$ climate experiment. J Clim 10:662-686. doi:10.1175/1520-0442(1997)010<0662:SDI $\mathrm{NMI}>2.0 . \mathrm{CO} ; 2$

Hall A (2014) Projecting regional change. Science 346:1461-1462. doi:10.1126/science.aaa0629

Hawkins E, Sutton R (2011) The potential to narrow uncertainty in projections of regional precipitation change. Clim Dyn 37:407418. doi:10.1007/s00382-010-0810-6

Held I, Soden B (2000) Water vapor feedback and global warming. Ann Rev Energy Environ 25:441-475. doi:10.1146/annurev. energy.25.1.441

Im ES, Coppola E, Giorgi F, Bi X (2010) Local effects of climate change over the Alpine region: a study with a high resolution regional climate model with a surrogate climate change scenario. Geophys Res Lett. doi:10.1029/2009GL041801

IPCC (2013) Annex I: atlas of global and regional climate projections, book section AI. Cambridge University Press, Cambridge

IPCC (2014) Climate change 2014: impacts, adaptation, and vulnerability. Part B: regional aspects. Contribution of working group II to the fifth assessment report of the intergovernmental panel on climate change. Cambridge University Press, Cambridge

Jacob D, Petersen J, Eggert B, Alias A, Christensen O, Bouwer L, Braun A, Colette A, DÃlquÃl M, Georgievski G, Georgopoulou E, Gobiet A, Menut L, Nikulin G, Haensler A, Hempelmann N, Jones C, Keuler K, Kovats S, Kröner N, Kotlarski S, Kriegsmann A, Martin E, Meijgaard E, Moseley C, Pfeifer S, Preuschmann S, Radermacher C, Radtke K, Rechid D, Rounsevell M, Samuelsson P, Somot S, Soussana JF, Teichmann C, Valentini R, Vautard R, Weber B, Yiou P (2014) Euro-cordex: new high-resolution climate change projections for European impact research. Reg Environ Change 14:563-578. doi:10.1007/s10113-013-0499-2

Jaeger EB, Anders I, Luethi D, Rockel B, Schaer C, Seneviratne SI (2008) Analysis of ERA40-driven CLM simulations for Europe. Meteorol Z 17:349-367. doi:10.1127/0941-2948/2008/0301

Joshi MM, Gregory JM, Webb MJ, Sexton DMH, Johns TC (2008) Mechanisms for the land/sea warming contrast exhibited by simulations of climate change. Clim Dyn 30:455-465. doi:10.1007/ s00382-007-0306-1

Kendon EJ, Rowell DP, Jones RG (2010) Mechanisms and reliability of future projected changes in daily precipitation. Clim Dyn 35:489-509. doi:10.1007/s00382-009-0639-z

Kharin VV, Zwiers FW, Zhang X, Wehner M (2013) Changes in temperature and precipitation extremes in the CMIP5 ensemble. Clim Change 119:345-357. doi:10.1007/s10584-013-0705-8

Kjellstrom E, Barring L, Jacob D, Jones R, Lenderink G, Schär C (2007) Modelling daily temperature extremes: recent climate and future changes over Europe. Clim Change 81:249-265. doi:10.1007/s10584-006-9220-5

Kotlarski S, Keuler K, Christensen OB, Colette A, Deque M, Gobiet A, Goergen K, Jacob D, Luethi D, van Meijgaard E, Nikulin G, Schär C, Teichmann C, Vautard R, Warrach-Sagi K, Wulfmeyer V (2014) Regional climate modeling on European scales: a joint standard evaluation of the EURO-CORDEX
RCM ensemble. Geosci Model Dev 7:1297-1333. doi:10.5194/ gmd-7-1297-2014

Lambert FH, Webb MJ, Joshi MM (2011) The relationship between land-ocean surface temperature contrast and radiative forcing. J Clim 24:3239-3256. doi:10.1175/2011JCLI3893.1

Levine XJ, Schneider T (2015) Baroclinic eddies and the extent of the Hadley circulation: an idealized GCM study. J Atmos Sci 72:2744-2761. doi:10.1175/JAS-D-14-0152.1

Lu J, Vecchi GA, Reichler T (2007) Expansion of the Hadley cell under global warming. Geophys Res Lett. doi:10.1029/200 6GL028443

Manabe S, Spelman M, Stouffer R (1992) Transient responses of a coupled ocean atmosphere model to gradual changes of atmospheric $\mathrm{CO}_{2}$. 2. Seasonal response. J Clim 5:105-126. doi:10.1175/1520-0442(1992)005<0105:TROACO >2.0.CO;2

Mbengue C, Schneider T (2013) Storm track shifts under climate change: what can be learned from large-scale dry dynamics. J Clim 26:9923-9930. doi:10.1175/JCLI-D-13-00404.1

Miralles DG, Teuling AJ, van Heerwaarden CC, de Arellano JV-G (2014) Mega-heatwave temperatures due to combined soil desiccation and atmospheric heat accumulation. Nat Geosci 7:345349. doi:10.1038/NGEO2141

Montesarchio M, Zollo AL, Bucchignani E, Mercogliano P, Castellari S (2014) Performance evaluation of high-resolution regional climate simulations in the Alpine space and analysis of extreme events. J Geophys Res Atmos 119:3222-3237. doi:10.1002/201 3JD021105

Moss RH, Edmonds JA, Hibbard KA, Manning MR, Rose SK, van Vuuren DP, Carter TR, Emori S, Kainuma M, Kram T, Meehl GA, Mitchell JFB, Nakicenovic N, Riahi K, Smith SJ, Stouffer RJ, Thomson AM, Weyant JP, Wilbanks TJ (2010) The next generation of scenarios for climate change research and assessment. Nature 463:747-756. doi:10.1038/nature08823

Orlowsky B, Seneviratne SI (2012) Global changes in extreme events: regional and seasonal dimension. Clim Change 110:669-696. doi:10.1007/s10584-011-0122-9

Parey S, Dacunha-Castelle D, Hoang TTH (2010) Mean and variance evolutions of the hot and cold temperatures in Europe. Clim Dyn 34:345-359. doi:10.1007/s00382-009-0557-0

Rajczak J, Pall P, Schär C (2013) Projections of extreme precipitation events in regional climate simulations for Europe and the Alpine Region. J Geophys Res Atmos 118:3610-3626. doi:10.1002/ jgrd.50297

Rasmussen R, Liu C, Ikeda K, Gochis D, Yates D, Chen F, Tewari M, Barlage M, Dudhia J, Yu W, Miller K, Arsenault K, Grubisic V, Thompson G, Gutmann E (2011) High-resolution coupled climate runoff simulations of seasonal snowfall over Colorado: a process study of current and warmer climate. J Clim 24:30153048. doi:10.1175/2010JCLI3985.1

Raval A, Ramanthan V (1989) Observational determination of the greenhouse-effect. Nature 342:758-761. doi:10.1038/342758a0

Rebetez M, Dupont O, Giroud M (2009) An analysis of the July 2006 heatwave extent in Europe compared to the record year of 2003. Theor Appl Climatol 95:1-7. doi:10.1007/s00704-007-0370-9

Rind D, Goldberg R, Hansen J, Rosenzweig C, Ruedy R (1990) Potential evapotranspiration and the likelihood of future drought. J Geophys Res Atmos 95:9983-10004. doi:10.1029/ JD095iD07p09983

Rockel B, Will A, Hense A (2008) The regional climate model COSMO-CLM (CCLM). Meteorol Z 17:347-348. doi:10.1127/0941-2948/2008/0309

Ross R, Elliott W, Seidel D, Grp PA-IM (2002) Lower-tropospheric humidity-temperature relationships in radiosonde observations and atmospheric general circulation models. J Hydrometeorol 3:26-38. doi:10.1175/1525-7541(2002)003<0026:LTHTRI >2.0. $\mathrm{CO} ; 2$ 
Rowell DP, Jones RG (2006) Causes and uncertainty of future summer drying over Europe. Clim Dyn 27:281-299. doi:10.1007/ s00382-006-0125-9

Sanchez-Gomez E, Somot S, Mariotti A (2009) Future changes in the Mediterranean water budget projected by an ensemble of regional climate models. Geophys Res Lett. doi:10.1029/200 9GL040120

Santer BD, Thorne PW, Haimberger L, Taylor KE, Wigley TML, Lanzante JR, Solomon S, Free M, Gleckler PJ, Jones PD, Karl TR, Klein SA, Mears C, Nychka D, Schmidt GA, Sherwood SC, Wentz FJ (2008) Consistency of modelled and observed temperature trends in the tropical troposphere. Int J Clim 28:17031722. doi: $10.1002 /$ joc. 1756

Schär C, Frei C, Luthi D, Davies H (1996) Surrogate climate-change scenarios for regional climate models. Geophys Res Lett 23:669-672. doi:10.1029/96GL00265

Schär C, Luthi D, Beyerle U, Heise E (1999) The soil-precipitation feedback: a process study with a regional climate model. J Clim 12:722-741. doi:10.1175/1520-0442(1999)012<0722:TSPFAP> 2.0.CO;2

Schär C, Vidale P, Luthi D, Frei C, Haberli C, Liniger M, Appenzeller C (2004) The role of increasing temperature variability in European summer heatwaves. Nature 427:332-336. doi:10.1038/ nature 02300

Schneider T, Bischoff T, Plotka H (2015) Physics of changes in synoptic midlatitude temperature variability. J Clim 28:2312-2331. doi:10.1175/JCLI-D-14-00632.1

Seneviratne S, Pal J, Eltahir E, Schär C (2002) Summer dryness in a warmer climate: a process study with a regional climate model. Clim Dyn 20:69-85. doi:10.1007/s00382-002-0258-4

Seneviratne SI, Koster RD, Guo Z, Dirmeyer PA, Kowalczyk E, Lawrence D, Liu P, Lu C-H, Mocko D, Oleson KW, Verseghy D (2006) Soil moisture memory in AGCM simulations: analysis of global land-atmosphere coupling experiment (GLACE) data. J Hydrometeorol 7:1090-1112. doi:10.1175/JHM533.1

Shepherd TG (2014) Atmospheric circulation as a source of uncertainty in climate change projections. Nat Geosci 7:703-708. doi:10.1038/NGEO2253

Sherwood S, Fu Q (2014) A drier future? Science 343:737-739. doi: $10.1126 /$ science. 1247620

Soden B, Jackson D, Ramaswamy V, Schwarzkopf M, Huang X (2005) The radiative signature of upper tropospheric moistening. Science 310:841-844. doi:10.1126/science.1115602

Sorland S, Sorteberg A (2015) Low-pressure systems and extreme precipitation in central india: sensitivity to temperature changes. Clim Dyn. doi:10.1007/s00382-015-2850-4
Stauffer R, Mayr GJ, Dabernig M, Zeileis A (2015) Somewhere over the rainbow how to make effective use of colors in meteorological visualizations. Bull Am Meteorol Soc 96:203-215. doi:10.1175/BAMS-D-13-00155.1

Stevens B, Giorgetta M, Esch M, Mauritsen T, Crueger T, Rast S, Salzmann M, Schmidt H, Bader J (2013) Atmospheric component of the MPI-M Earth System Model: ECHAM6. J Adv Model Earth Syst 5(2):146-172

Stocker T, Qin D, Plattner GK, Alexander L, Allen S, Bindoff N, Breon FM, Church J, Cubasch U, Emori S, Forster P, Friedlingstein P, Gillett N, Gregory J, Hartmann D, Jansen E, Kirtman B, Knutti R, Krishna Kumar K, Lemke P, Marotzke J, Masson-Delmotte V, Meehl G, Mokhov I, Piao S, Ramaswamy V, Randall D, Rhein M, Rojas M, Sabine C, Shindell D, Talley L, Vaughan D, Xie SP (2013) Technical summary, book section TS. Cambridge University Press, Cambridge, pp 33-115

Tanré D, Geleyn J, Slingo J (1984) First results of the introduction of an advanced aerosol-radiation interaction in ECMWF low resolution global model. In: Gerber H, Deepak A (eds) Aerosols and their climatic effects. Deepak Publishing, Hampton, pp 133-177

Tett S, Mitchell J, Parker D, Allen M (1996) Human influence on the atmospheric vertical temperature structure: detection and observations. Science 274:1170-1173. doi:10.1126/ science. 274.5290 .1170

Vallis GK, Zurita-Gotor P, Cairns C, Kidston J (2015) Response of the large-scale structure of the atmosphere to global warming. Q J R Meteorol Soc 141:1479-1501. doi:10.1002/qj.2456

van Ulden A, Lenderink G, van den Hurk B, van Meijgaard E (2007) Circulation statistics and climate change in Central Europe: PRUDENCE simulations and observations. Clim Change 81:179-192. doi:10.1007/s10584-006-9212-5

Vautard R, Gobiet A, Jacob D, Belda M, Colette A, Deque M, Fernandez J, Garcia-Diez M, Goergen K, Guettler I, Halenka T, Karacostas T, Katragkou E, Keuler K, Kotlarski S, Mayer S, van Meijgaard E, Nikulin G, Patarcic M, Scinocca J, Sobolowski S, Suklitsch M, Teichmann C, Warrach-Sagi K, Wulfmeyer V, Yiou $P$ (2013) the simulation of european heat waves from an ensemble of regional climate models within the euro-cordex project. Clim Dyn 41:2555-2575. doi:10.1007/s00382-013-1714-Z

Vidale PL, Luethi D, Wegmann R, Schär C (2007) european summer climate variability in a heterogeneous multi-model ensemble. Clim Change 81:209-232. doi:10.1007/s10584-006-9218-z

Woollings T (2008) Vertical structure of anthropogenic zonal-mean atmospheric circulation change. Geophys Res Lett. doi:10.1029/ 2008GL034883 